\title{
Validity of self-reported weight and height in Austrian adults: sociodemographic determinants and consequences for the classification of BMl categories
}

\author{
Franziska Großschädl ${ }^{1, *}$, Bernd Haditsch ${ }^{2}$ and Willibald J Stronegger ${ }^{3}$ \\ ${ }^{1}$ Clinical Department of Gynaecology, Medical University Graz, Auenbruggerplatz 14, A-8010 Graz, Austria: \\ ${ }^{2}$ Institute of Preventive Medicine, Graz, Austria: ${ }^{3}$ Institute of Social Medicine and Epidemiology, \\ Medical University Graz, Graz, Austria
}

Submitted 31 January 2011: Accepted 14 June 2011: First published online 11 August 2011

\begin{abstract}
Objective: Epidemiological studies have shown that adults tend to underestimate their weight and overestimate their height. This may lead to a misclassification of their BMI in studies based on self-reported data. The aim of the present study was to assess the validity of self-reported weight and height in Austrian adults.

Design: Data on weight, height, health behaviour and sociodemographic characteristics of adults were collected in a standardized procedure via a self-filling questionnaire and a medical examination including measurements of weight and height.

Setting: A publicly accessible out-patient clinic in southern Austria.

Subjects: Austrian residents ( $n$ 473) aged 18 years and older who attended a health check participated in the study.

Results: The mean difference between reported and measured BMI was not significant in younger adults ( $<35$ years: mean difference $\left.-0 \cdot 21 \mathrm{~kg} / \mathrm{m}^{2} ; P<0 \cdot 08\right)$ but increased significantly with age ( $\geq 55$ years: mean difference $-0.68 \mathrm{~kg} / \mathrm{m}^{2}$; $P<0 \cdot 001)$. The prevalence of normal weight $\left(\mathrm{BMI}=18 \cdot 5-24 \cdot 9 \mathrm{~kg} / \mathrm{m}^{2}\right)$ and overweight $\left(\mathrm{BMI}=25 \cdot 0-29 \cdot 9 \mathrm{~kg} / \mathrm{m}^{2}\right)$ was overestimated based on the selfreported data on BMI, while that for underweight $\left(\mathrm{BMI}<18.5 \mathrm{~kg} / \mathrm{m}^{2}\right)$ and obesity $\left(\mathrm{BMI} \geq 30 \cdot 0 \mathrm{~kg} / \mathrm{m}^{2}\right)$ was underestimated $(P<0 \cdot 001)$. The self-reported data showed an obesity prevalence of $12.5 \%$, while measurement showed a prevalence of $15 \cdot 4 \%(P<0 \cdot 001)$.

Conclusions: Our results indicate that prevalence rates of obesity are probably underestimated for Austrian adults when using self-reported weight and height information. The deviations from the measured data clearly increased with age. Analyses based on self-reported data should therefore be adjusted for the age dependency of the validity.
\end{abstract}

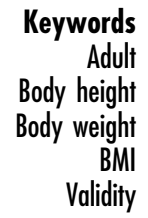

The prevalence of overweight and obesity is alarmingly high in the industrialized countries of North America and Europe ${ }^{(1-3)}$. Overweight and obesity are major risk factors for a number of chronic sequelae such as diabetes mellitus type 2, CVD, asthma, adipohepatic conditions, dyslipidaemia and malignant tumours ${ }^{(4-7)}$ and are now even epidemic in Europe. They account for 10 to $13 \%$ of deaths and for 2 to $8 \%$ of health expenditures ${ }^{(1)}$. It is assumed that in the twenty-seven countries which belong to the European Union, about 200 million people are overweight or obese. This corresponds to almost half of the population within the European Union ${ }^{(8)}$.

Many population-based surveys regarding BMI utilize self-reported instead of anthropometric measured data, for convenience and financial reasons ${ }^{(5,9)}$. Information from self-reported data concerning body weight and height is often incorrect. Studies from different countries have found that subjects tend to over-report their body height $^{(10-21)}$ and under-report their body weight ${ }^{(10-23)}$. Especially older subjects overestimate their height ${ }^{(12,16,20)}$. Women in particular assess their weight lower than it actually is ${ }^{(3,10,23)}$, and men more often over-report their body height ${ }^{(15,20)}$. Some of these studies have shown, in contrast with anthropometric measurements, that the overweight and obesity prevalence in self-reported data is usually lower ${ }^{(10,11,13,19)}$.

The validity of self-reported weight and height has so far not been investigated in Austrian adults. The purpose of the current study was to evaluate the validity of selfreported body weight and height among adults in Austria 
and to determine whether the validity depends upon readily available individual characteristics such as age, sex, educational level and smoking behaviour. In addition, we wished to assess the accuracy of self-reported data and its influence on the classification of different BMI categories (underweight, normal weight, overweight and obesity) in comparison with measured data.

\section{Materials and methods}

\section{Procedure and study population}

The data for the current validation study were collected in cooperation with the Institute of Preventive Medicine, between 25 January and 21 February 2010, in Graz, a middle-sized city in southern Austria. The Institute of Preventive Medicine organizes health checks at its outpatient clinic. These are open to all Austrian residents aged 18 years and older, regardless of status (i.e. whether insured or uninsured). Persons who attended a health check were asked beforehand to fill in an anonymous single-sheet questionnaire, providing information such as their actual weight in kilograms without clothes, their height in centimetres without shoes as well as other personal characteristics (such as sex, age, level of education and smoking behaviour).

Once the persons agreed to participate, they were first prompted to complete the questionnaire. After that they were invited to start the health checks. These were carried out in examination rooms by different physicians (six physicians in total), who performed the weight and height measurements according to a standardized procedure. The completed questionnaires were forwarded to the respective health professional. After the health check, the health professional noted the measured body weight and height of the participants in the questionnaire.

A total of 595 questionnaires were distributed to persons who attended the health examination at the out-patient unit of the Institute of Preventive Medicine in Graz. Five hundred and fifty-three persons actually participated (257 women; 277 men; nineteen failed to specify their gender), thus yielding a response rate of $92.9 \%$. Eighty of those adults were excluded from statistical analysis because of missing data on their weight and/or height and their gender. Thus 473 participants were eligible for analysis. Of the study population, $53.3 \%$ were male. The mean age of the participants was $46 \cdot 2$ years (women: 45 (SD 15) years; men: 47 (SD 14) years), with age overall ranging from 20 to 84 years. A total of $93.9 \%$ had Austrian citizenship; the other participants came from other European countries. About $47 \cdot 3 \%$ of the adults lived in Graz, $51 \cdot 0 \%$ in the surroundings of Graz and $1.7 \%$ failed to answer this question. The highest educational level of the participants was a completed vocational school degree (42.5\%). The majority reported that they had never smoked (44.8\%), followed by those who had given up smoking (27.9\%).

\section{Ethical approval}

Participation in the study was voluntary. The participants were previously informed that their data would not be disclosed to third parties and would be kept anonymous. The current validation study forms part of an investigation into Austrian trend analyses regarding obesity. This survey was approved by the ethics commission of the Medical University of Graz (EK-number: 23-172 ex 10/11).

\section{Measurements and variables}

During the health examinations, body weight and height were measured in a standardized procedure with participants wearing underwear and no shoes. The variable weight was measured using a digital scale to the nearest $1 \mathrm{~kg}$. Height was measured with the participants standing without shoes and feet together, to the nearest $1 \mathrm{~cm}$.

BMI was calculated as body weight divided by body height squared $\left(\mathrm{kg} / \mathrm{m}^{2}\right)$. The definition of BMI categories was made according to the WHO criteria ${ }^{(24)}$ : underweight was defined as BMI $<18 \cdot 5 \mathrm{~kg} / \mathrm{m}^{2}$, normal weight as BMI $=$ $18 \cdot 5-24.9 \mathrm{~kg} / \mathrm{m}^{2}$, overweight as $\mathrm{BMI}=25 \cdot 0-29 \cdot 9 \mathrm{~kg} / \mathrm{m}^{2}$, obesity class 1 as BMI $=30 \cdot 0-34 \cdot 9 \mathrm{~kg} / \mathrm{m}^{2}$, obesity class 2 as $\mathrm{BMI}=35 \cdot 0-39 \cdot 9 \mathrm{~kg} / \mathrm{m}^{2}$ and obesity class 3 as BMI $\geq 40 \cdot 0 \mathrm{~kg} / \mathrm{m}^{2}$.

Participants were categorized into four age groups. These comprised: less than 35 years ( $n 132)$, 35-44 years ( $n$ 124), 45-54 years $(n 100)$ and 55 years and older $(n 117)$.

Education was measured as the highest level reached and then categorized in the following groups: primary school ( $n$ 49), vocational school ( $n$ 201), commercial or professional school ( $n$ 65), secondary school with school completion examination ( $n$ 82), university or college of higher education ( $n$ 61) and other education after school completion examination ( $n 9)$. Six participants opted not to report their educational level.

Smoking behaviour was recorded as occasionally ( $n$ 27), up to 10 cigarettes daily ( $n$ 34), 11 to 20 cigarettes daily ( $n$ 39), more than 20 cigarettes daily ( $n$ 14), given up ( $n$ 132) or never smoked ( $n$ 212). Fifteen persons opted not to specify their smoking behaviour.

\section{Statistical analyses}

Self-reported and measured BMI were calculated using self-reported and measured height and weight. The reported and measured BMI values were classified into the different weight classes: underweight, normal weight, overweight and obese (class 1 to 3 ). The prevalences were stratified by sex and gender.

Multiple linear regression analysis was used to identify factors associated with the difference between self-reported and measured BMI. The model included the following independent variables: sex (with the female as reference), age group (with the youngest age group of less than 35 years as reference), educational level (with primary school as reference) and smoking behaviour (with smoking occasionally as reference). 
In addition, agreement between self-reported and measured BMI was assessed using the Bland-Altman method $^{(25,26)}$. In assessing the agreement between two methods of measurement, the bias and mean variation of individual measurement differences are of importance. The Bland-Altman plot considers these two aspects and provides an easy way to represent and quantify the conformity of measurement methods. All observed outliers were included in the analysis, because their underlying reported and measured weight and height values were in a plausible range.

Paired-sample $t$ tests were conducted in order to detect significant differences between measured and reported anthropometrics. In order to compare reported with measured prevalences of different BMI categories the nptrend procedure of Stata/SE was applied, which performs Cuzick's non-parametric test for trends across ordered groups. This test is an extension of the Wilcoxon rank sum test ${ }^{(27)}$. A $P$ value of 0.05 was used as a threshold for statistical significance.

Data management and statistical analyses were conducted using the statistical software packages SPSS ${ }^{\circledR}$ for Windows version $17 \cdot 0$ (SPSS Inc., Chicago, IL, USA) and Stata/SE for Windows version $1 \cdot 1$ (StataCorp., College Station, TX, USA).

\section{Results}

\section{Descriptive statistics of self-reported and measured data}

Age- and sex-specific means and differences in selfreported $v$. measured weight and height are presented in Table 1. In total, self-reported mean weight was significantly lower than measured mean weight $(P<0 \cdot 05)$. However, both women and men overestimated their body height by about $1 \mathrm{~cm}(P<0 \cdot 05)$.

Table 2 shows mean values and differences for selfreported $v$. measured BMI. The mean BMI values calculated from self-reported data were lower than the measurementbased BMI values. Self-reported weight and height resulted in a mean BMI of $25.04 \mathrm{~kg} / \mathrm{m}^{2}$, while measurements showed a mean BMI of $25 \cdot 44 \mathrm{~kg} / \mathrm{m}^{2}$. In total a difference of $-0.40 \mathrm{~kg} / \mathrm{m}^{2}$ was found between reported and measured BMI values $(P<0 \cdot 05)$.

The biggest difference between self-reported and measured body weight was found for women in the age group of 55 years and older $(-1.06 \mathrm{~kg}, P<0.05)$. In men the biggest difference was found in the age group 45 to 54 years $(-0.73 \mathrm{~kg}, P<0.05)$. Body height was most frequently overestimated by participants aged 55 years and older. This applied to both women and men (women: $+1.44 \mathrm{~cm}, P<0 \cdot 05$; men: $+1.46 \mathrm{~cm}, P<0.05$ ). The greatest deviations between self-reported and measured BMI emerged among the oldest study participants (women: $-0.87 \mathrm{~kg} / \mathrm{m}^{2}, P<0.05$; men: $\left.-0.53 \mathrm{~kg} / \mathrm{m}^{2}, P<0 \cdot 05\right)$.

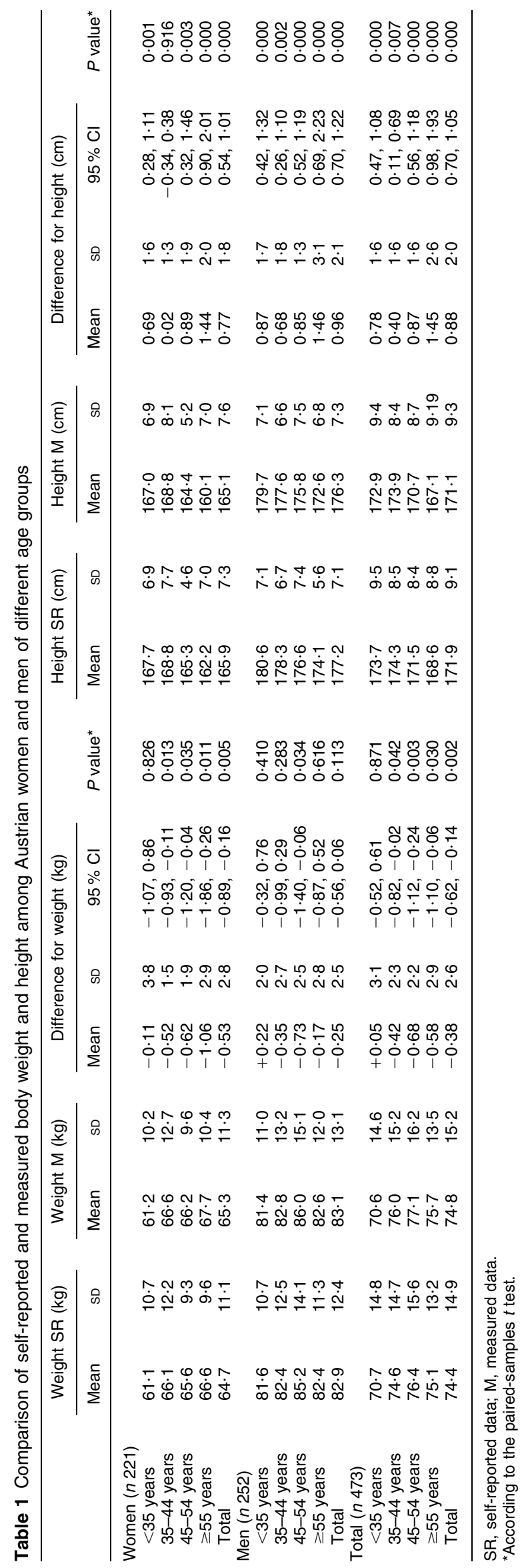


Table 2 Comparison of self-reported and measured BMI among Austrian women and men of different age groups

\begin{tabular}{|c|c|c|c|c|c|c|c|c|}
\hline & \multicolumn{2}{|c|}{ BMI SR $\left(\mathrm{kg} / \mathrm{m}^{2}\right)$} & \multicolumn{2}{|c|}{ BMI M $\left(\mathrm{kg} / \mathrm{m}^{2}\right)$} & \multicolumn{3}{|c|}{ Difference for BMI $\left(\mathrm{kg} / \mathrm{m}^{2}\right)$} & \multirow[b]{2}{*}{$P$ value $^{\star}$} \\
\hline & Mean & SD & Mean & SD & Mean & $\mathrm{SD}$ & $95 \% \mathrm{Cl}$ & \\
\hline \multicolumn{9}{|l|}{ Women (n 221) } \\
\hline$<35$ years & $21 \cdot 7$ & $3 \cdot 1$ & $21 \cdot 9$ & $3 \cdot 0$ & -0.23 & $1 \cdot 5$ & $-0.61,0.15$ & 0.238 \\
\hline $35-44$ years & $23 \cdot 1$ & $3 \cdot 2$ & $23 \cdot 3$ & $3 \cdot 4$ & $-0 \cdot 19$ & 0.6 & $-0.37,-0.02$ & 0.033 \\
\hline $45-54$ years & $24 \cdot 0$ & $3 \cdot 0$ & $24 \cdot 5$ & $3 \cdot 3$ & -0.50 & 0.8 & $-0.74,-0.25$ & 0.000 \\
\hline$\geq 55$ years & $25 \cdot 4$ & $3 \cdot 6$ & $26 \cdot 2$ & $4 \cdot 0$ & -0.87 & $1 \cdot 1$ & $-1 \cdot 17,-0.56$ & 0.000 \\
\hline Total & 23.5 & $3 \cdot 6$ & $23 \cdot 9$ & $3 \cdot 8$ & -0.43 & $1 \cdot 1$ & $-0.58,-0.28$ & 0.000 \\
\hline \multicolumn{9}{|l|}{ Men (n 252) } \\
\hline$<35$ years & $25 \cdot 0$ & $2 \cdot 9$ & $25 \cdot 2$ & $3 \cdot 1$ & $-0 \cdot 18$ & 0.9 & $-0.43,0.06$ & $0 \cdot 143$ \\
\hline $35-44$ years & $25 \cdot 9$ & $3 \cdot 3$ & $26 \cdot 2$ & $3 \cdot 6$ & -0.31 & $1 \cdot 2$ & $-0.59,-0.04$ & 0.026 \\
\hline $45-54$ years & $27 \cdot 3$ & $3 \cdot 9$ & $27 \cdot 8$ & $4 \cdot 2$ & -0.49 & 0.9 & $-0.74,-0.24$ & 0.000 \\
\hline$\geq 55$ years & $27 \cdot 2$ & $3 \cdot 3$ & $27 \cdot 7$ & $3 \cdot 6$ & -0.53 & $1 \cdot 1$ & $-0.81,-0.25$ & 0.000 \\
\hline Total & $26 \cdot 4$ & $3 \cdot 5$ & $26 \cdot 8$ & 3.9 & -0.38 & $1 \cdot 1$ & $-0.51,-0.25$ & 0.000 \\
\hline \multicolumn{9}{|l|}{ Total (n 473) } \\
\hline$<35$ years & $23 \cdot 2$ & $3 \cdot 4$ & $23 \cdot 4$ & $3 \cdot 4$ & -0.21 & $1 \cdot 3$ & $-0.43,-0.06$ & 0.078 \\
\hline 35-44 years & $24 \cdot 7$ & $3 \cdot 5$ & $25 \cdot 0$ & $3 \cdot 8$ & -0.26 & $1 \cdot 0$ & $-0.59,-0.09$ & 0.003 \\
\hline 45-54 years & $25 \cdot 8$ & $3 \cdot 9$ & $26 \cdot 3$ & $4 \cdot 1$ & -0.49 & 0.9 & $-0.67,-0.32$ & 0.000 \\
\hline$\geq 55$ years & $26 \cdot 3$ & $3 \cdot 6$ & $27 \cdot 0$ & $3 \cdot 9$ & -0.68 & $1 \cdot 1$ & $-0.89,-0.48$ & 0.000 \\
\hline Total & $25 \cdot 0$ & $3 \cdot 8$ & $25 \cdot 4$ & $4 \cdot 1$ & $-0 \cdot 40$ & $1 \cdot 1$ & $-0.50,-0.30$ & 0.000 \\
\hline
\end{tabular}

SR, self-reported data; $M$, measured data.

${ }^{*}$ According to the paired-samples $t$ test.

Table 3 Determinants of the difference between self-reported and measured BMI among Austrian adults (multiple linear regression analysis; $n$ 452)

\begin{tabular}{|c|c|c|c|c|}
\hline Variable & $B\left(\mathrm{~kg} / \mathrm{m}^{2}\right)$ & $95 \% \mathrm{Cl}$ for $B$ & SD & $P$ value \\
\hline Intercept & $-0 \cdot 129$ & $-0.78,0.53$ & 0.33 & 0.699 \\
\hline \multicolumn{5}{|l|}{ Sex } \\
\hline Female & Ref. & & & \\
\hline Male & -0.04 & $-0.28,0.20$ & $0 \cdot 12$ & $0 \cdot 74$ \\
\hline \multicolumn{5}{|l|}{ Age group } \\
\hline$<35$ years & Ref. & & & \\
\hline $35-44$ years & $-0 \cdot 12$ & $-0.44,0.20$ & $0 \cdot 16$ & 0.46 \\
\hline $45-54$ years & -0.39 & $-0.74,-0.05$ & $0 \cdot 18$ & 0.03 \\
\hline$\geq 55$ years & $-0 \cdot 70$ & $-1.05,-0.36$ & $0 \cdot 18$ & 0.00 \\
\hline \multicolumn{5}{|l|}{ Educational level } \\
\hline Primary school & Ref. & & & \\
\hline Vocational school & -0.08 & $-0.48,0.32$ & $0 \cdot 20$ & 0.69 \\
\hline Commercial or professional school & $-0 \cdot 10$ & $-0.56,0.36$ & 0.23 & $0 \cdot 67$ \\
\hline Secondary school with school completion examination & -0.24 & $-0.70,0.22$ & $0 \cdot 23$ & $0 \cdot 30$ \\
\hline University of higher education & -0.22 & $-0.71,0.27$ & $0 \cdot 25$ & 0.37 \\
\hline Other education after school completion examination & $-0 \cdot 17$ & $-1 \cdot 05,0 \cdot 70$ & 0.44 & $0 \cdot 70$ \\
\hline \multicolumn{5}{|l|}{ Smoking behaviour } \\
\hline Occasionally smoking & Ref. & & & \\
\hline Smoking up to 10 cigarettes daily & -0.06 & $-0.68,0.55$ & $0 \cdot 31$ & 0.84 \\
\hline Smoking 11 to 20 cigarettes daily & $-0 \cdot 10$ & $-0.70,0.49$ & $0 \cdot 30$ & $0 \cdot 73$ \\
\hline Smoking more than 20 cigarettes daily & 0.07 & $0.73,0.86$ & $0 \cdot 40$ & 0.87 \\
\hline Given up smoking & $0 \cdot 14$ & $-0.36,0.63$ & $0 \cdot 25$ & 0.59 \\
\hline Never smoked & $0 \cdot 18$ & $-0.31,0.66$ & $0 \cdot 25$ & $0 \cdot 48$ \\
\hline
\end{tabular}

$B$, coefficient of regression; Ref., reference category.

\section{Determinants of validity}

In order to identify determinants of validity, a multiple linear regression analysis was performed with sex, educational level, smoking behaviour and age group as independent variables and differences between self-reported and measured BMI as dependent variable. The regression analysis results are presented in Table 3 .

The model explained about $5 \%$ of the variance $\left(R^{2}=0.050\right)$ and included 452 persons. There was no gender effect $(P=0 \cdot 74)$. Age was the only predictor included in the regression model that was statistically significantly associated with the difference between measured and reported BMI $(P<0 \cdot 001)$. The second age group (36-45 years) showed no greater difference between self-reported and measured BMI data $\left(B=-0 \cdot 12 \mathrm{~kg} / \mathrm{m}^{2}\right.$, $P=0.461)$ than the youngest age group $(<35$ years $)$, whereas the difference in the two older age groups increased significantly (age group 46-55 years: $B=$ $-0.39 \mathrm{~kg} / \mathrm{m}^{2}, P=0 \cdot 026$; age group 55 years and older: $\left.B=-0 \cdot 70 \mathrm{~kg} / \mathrm{m}^{2}, P<0 \cdot 001\right)$. 
(a)

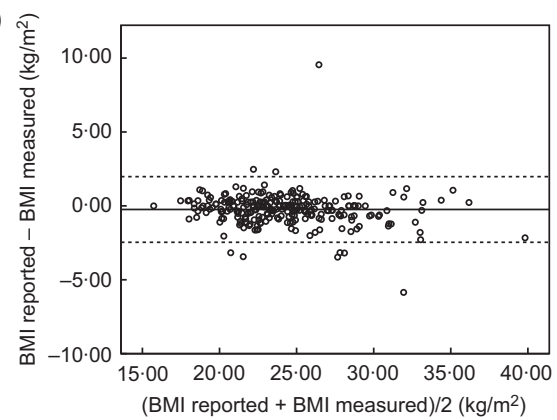

(b)

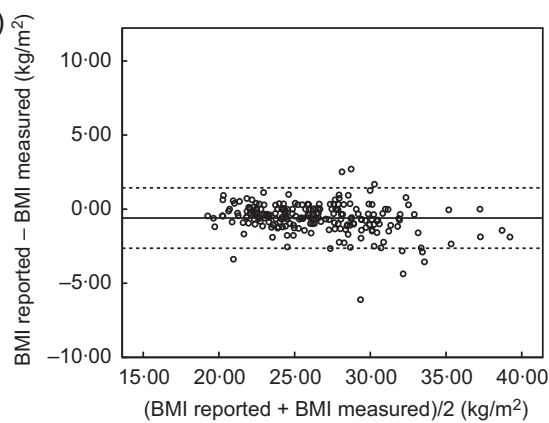

Fig. 1 Bland-Altman plot for analysis of agreement between self-reported and measured BMI in Austrian adults by age: (a) less than 45 years; (b) 45 years and older. — represents mean difference; - - - - represent upper and lower limits of agreement (mean difference $\pm 2 \mathrm{SD}$ )

\section{Agreement between self-reported and measured data}

Figure 1 illustrates the agreement between self-reported and measured BMI separately for participants up to 45 years of age (Fig. 1(a)) and participants aged 45 years and older (Fig. 1(b)). The solid line in the plots represents the mean difference between BMI measurements and the mean of both measurements. The dashed lines represent the $95 \%$ limits of agreement.

The mean differences in the Bland-Altman plots are close to zero, indicating a very good agreement between self-reported and measured data at population level. The ranges of misreported BMI values are also quite small. This means good agreement at the individual level. The $95 \%$ CI for the BMI values in younger study participants indicate that individual variability between the two BMI measurements was between $-2 \cdot 46 \mathrm{~kg} / \mathrm{m}^{2}$ and $+1.98 \mathrm{~kg} / \mathrm{m}^{2}$. The mean bias was $-0 \cdot 24 \mathrm{~kg} / \mathrm{m}^{2}$. The comparison of the plots shows that the agreement between reported and measured BMI is lower in older study participants (mean difference: $-0.60 \mathrm{~kg} / \mathrm{m}^{2}, 95 \%$ CI $-2 \cdot 64,1 \cdot 44 \mathrm{~kg} / \mathrm{m}^{2}$ ).

\section{Consequences of self-reporting on BMI categories}

Anthropometric measurements showed that most of the participants were categorized as having normal weight $(45.9 \%)$. The prevalence of underweight and obesity was underestimated when based on self-reported body weight and height (Table 4). Especially among the older participants ( 45 years and older), obesity prevalences were underestimated in the self-reporting procedure $(P<0 \cdot 001)$, e.g. $15 \cdot 7 \% v .18 \cdot 4 \%$ for obesity class 1 . In the younger age groups no significant differences in BMI categories $(P=0 \cdot 425)$ were found.

\section{Discussion}

The present study is the first to investigate the validity of self-reported weight and height for adults in Austria. We have found high correlations between self-reported and measured weight, height and BMI in younger adults. Recent publications have shown that female adults tend to under-report their weight, while men more often overreport their height ${ }^{(3,15,20)}$. In our study we also found a difference between women and men in terms of the degree of inaccuracy in reporting weight and height. The mean weight for the female study participants was $64.7 \mathrm{~kg}$ and the difference between self-reported and measured weight was $-0.53 \mathrm{~kg}$, whereas the difference in men amounted to only $-0 \cdot 25 \mathrm{~kg}$ (self-reported mean weight: $82 \cdot 1 \mathrm{~kg}$ ). In comparison with our study, Visscher et al. ${ }^{(13)}$ recorded considerably higher differences between reported and measured weight. They used data from a Dutch population study for which interviews were conducted face-to-face at the participants' homes. Their study found a difference of $1.4 \mathrm{~kg}$ for women. The difference for men was slightly lower $(1 \cdot 0 \mathrm{~kg})$. One possible reason for the higher difference in the Dutch study might be that people are more likely to underestimate their weight when interviewed in their home. It seems that people tend to assess their weight more accurately in an out-patient setting.

Furthermore, we found a reported height with a mean value of $165 \cdot 9 \mathrm{~cm}$ for women and $177 \cdot 2 \mathrm{~cm}$ for men. Mean differences in body height were rather higher among men $(0.77 \mathrm{~cm} v .0 .96 \mathrm{~cm}, P<0.001)$ than among women. This contrasts with the results of a Swiss study ${ }^{(10)}$ showing women more likely to overestimate their height. Also the mean differences between reported and measured height in the Swiss study were much higher (women: $2.5 \mathrm{~cm}$; men: $1.9 \mathrm{~cm}$ ).

Our results indicate that the differences between selfreported and measured body weight and height in our Austrian adults were much smaller than in similar surveys. There was a relatively minor difference between women and men in self-reported and measured mean BMI data (women: $-0 \cdot 43 \mathrm{~kg} / \mathrm{m}^{2}$; men: $-0 \cdot 38 \mathrm{~kg} / \mathrm{m}^{2}$ ). Multiple linear regression analysis revealed no gender differences regarding the difference between self-reported and measured BMI. This outcome contradicts the results of other studies ${ }^{(20,26)}$. Glaesmer and Brähler ${ }^{(20)}$ found that 
Table 4 Number and proportion of Austrian adults classified in different BMI categories according to self-reported and measured values of weight and height, using international WHO classification cut-off points, separately for younger and older participants and for women and men

\begin{tabular}{|c|c|c|c|c|c|c|}
\hline & \multicolumn{3}{|c|}{$\begin{array}{l}\text { BMI category based } \\
\text { on self-reported BMI }\end{array}$} & \multicolumn{3}{|c|}{$\begin{array}{l}\text { BMI category based } \\
\text { on measured BMI }\end{array}$} \\
\hline & $n$ & $\%$ & $95 \% \mathrm{Cl}$ & $n$ & $\%$ & $95 \% \mathrm{Cl}$ \\
\hline \multicolumn{7}{|c|}{ Participants aged $<45$ years $\left(P^{*}=0.001 ; Z \dagger=13.25\right)$} \\
\hline Underweight & 6 & $2 \cdot 3$ & $0 \cdot 5,4 \cdot 2$ & 7 & $2 \cdot 7$ & $0 \cdot 7,4 \cdot 7$ \\
\hline Normal weight & 144 & $56 \cdot 3$ & $50 \cdot 1,62 \cdot 3$ & 142 & $55 \cdot 5$ & $49 \cdot 3,61 \cdot 6$ \\
\hline Overweight & 86 & $33 \cdot 6$ & $27 \cdot 8,39 \cdot 4$ & 83 & $32 \cdot 4$ & $26 \cdot 7,38 \cdot 1$ \\
\hline Obese class 1 & 16 & $6 \cdot 3$ & $3 \cdot 3,9 \cdot 2$ & 20 & $7 \cdot 8$ & $4 \cdot 5,11 \cdot 1$ \\
\hline Obese class 2 & 4 & $1 \cdot 6$ & $0.03,3 \cdot 1$ & 3 & $1 \cdot 2$ & $0 \cdot 1,2 \cdot 5$ \\
\hline Obese class 3 & 0 & 0 & & 1 & $0 \cdot 4$ & $0 \cdot 4,1 \cdot 1$ \\
\hline \multicolumn{7}{|c|}{ Participants aged $\geq 45$ years $\left(P^{*}<0.001 ; Z \dagger=12.84\right)$} \\
\hline Underweight & 0 & 0 & & 0 & 0 & \\
\hline Normal weight & 87 & $40 \cdot 1$ & $33 \cdot 5,46 \cdot 6$ & 75 & $34 \cdot 6$ & $28 \cdot 2,40 \cdot 9$ \\
\hline Overweight & 91 & 41.9 & $35 \cdot 3,48 \cdot 5$ & 93 & $42 \cdot 9$ & $36 \cdot 2,49 \cdot 5$ \\
\hline Obese class 1 & 34 & $15 \cdot 7$ & $10 \cdot 8,20 \cdot 5$ & 40 & $18 \cdot 4$ & $13 \cdot 2,23 \cdot 6$ \\
\hline Obese class 2 & 5 & $2 \cdot 3$ & $0 \cdot 3,4 \cdot 3$ & 8 & $3 \cdot 7$ & $1 \cdot 1,6 \cdot 2$ \\
\hline Obese class 3 & 0 & 0 & & 1 & 0.5 & $0 \cdot 4,1 \cdot 4$ \\
\hline \multicolumn{7}{|c|}{ Women $\left(P^{*}<0.001 ; Z \dagger=12 \cdot 20\right)$} \\
\hline Underweight & 6 & $2 \cdot 7$ & $0 \cdot 56,4 \cdot 87$ & 6 & $2 \cdot 7$ & $0.6,4.9$ \\
\hline Normal weight & 152 & $68 \cdot 8$ & $62 \cdot 6,74 \cdot 9$ & 141 & $63 \cdot 8$ & $57 \cdot 4,70 \cdot 2$ \\
\hline Overweight & 47 & $21 \cdot 3$ & $15 \cdot 9,26 \cdot 7$ & 51 & $23 \cdot 1$ & $17 \cdot 5,28 \cdot 7$ \\
\hline Obese class 1 & 14 & $6 \cdot 3$ & $3 \cdot 1,9 \cdot 6$ & 19 & $8 \cdot 6$ & $4 \cdot 9,12 \cdot 3$ \\
\hline Obese class 2 & 2 & 0.9 & $0 \cdot 4,2 \cdot 2$ & 3 & $1 \cdot 4$ & $0.2,2 \cdot 9$ \\
\hline Obese class 3 & 0 & 0 & & 1 & 0.5 & $0 \cdot 4,1 \cdot 3$ \\
\hline \multicolumn{7}{|c|}{$\operatorname{Men}\left(P^{*}=0.001 ; Z \uparrow=13.72\right)$} \\
\hline Underweight & 0 & 0 & & 1 & 0.4 & $0 \cdot 4,1 \cdot 2$ \\
\hline Normal weight & 79 & $31 \cdot 3$ & $25 \cdot 6,37 \cdot 1$ & 76 & $30 \cdot 2$ & $24 \cdot 5,35 \cdot 9$ \\
\hline Overweight & 130 & $51 \cdot 6$ & $45 \cdot 4,57 \cdot 8$ & 125 & $49 \cdot 6$ & $43 \cdot 4,55 \cdot 8$ \\
\hline Obese class 1 & 36 & $14 \cdot 3$ & $10 \cdot 0,18 \cdot 6$ & 41 & $16 \cdot 3$ & $11 \cdot 7,20 \cdot 8$ \\
\hline Obese class 2 & 7 & $2 \cdot 8$ & $0 \cdot 7,4 \cdot 8$ & 8 & $3 \cdot 2$ & $1 \cdot 0,5 \cdot 3$ \\
\hline Obese class 3 & 0 & 0 & & 1 & 0.4 & $0 \cdot 4,1 \cdot 1$ \\
\hline \multicolumn{7}{|c|}{ Total $\left(P^{*}<0.001 ; Z \dagger=18.65\right)$} \\
\hline Underweight & 6 & $1 \cdot 3$ & $0 \cdot 3,2 \cdot 3$ & 7 & 1.5 & $0 \cdot 0,2 \cdot 6$ \\
\hline Normal weight & 231 & $48 \cdot 8$ & $44 \cdot 3,53 \cdot 4$ & 217 & $45 \cdot 9$ & $41 \cdot 4,50 \cdot 4$ \\
\hline Overweight & 177 & $37 \cdot 4$ & $33 \cdot 0,41 \cdot 8$ & 176 & $37 \cdot 2$ & $32 \cdot 8,41 \cdot 6$ \\
\hline Obese class 1 & 50 & $10 \cdot 6$ & $7 \cdot 8,13 \cdot 4$ & 60 & $12 \cdot 7$ & $9 \cdot 7,15 \cdot 7$ \\
\hline Obese class 2 & 9 & 1.9 & $0.1,0.3$ & 11 & $2 \cdot 3$ & $1 \cdot 0,3 \cdot 7$ \\
\hline Obese class 3 & 0 & 0 & & 2 & 0.4 & $0 \cdot 2,1 \cdot 0$ \\
\hline
\end{tabular}

${ }^{*}$ According to the Cuzick test for trend.

tAccording to the Cuzick test for trend.

sex and age had a significant interaction effect on the deviations between reported and measured BMI values. In their study, which was conducted in Germany, women more frequently under-reported their BMI. Their study also showed the difference in BMI to increase with age. The highest BMI difference $\left(-2 \cdot 39 \mathrm{~kg} / \mathrm{m}^{2}\right)$ was found in the age group from 60 to 69 years.

When grouping our study participants in different age categories, we also found the highest variations between reported and measured data in the oldest age group (participants 55 years and older). BMI was most often statistically significantly over-reported by this age group (mean difference: $-0.68 \mathrm{~kg} / \mathrm{m}^{2}$ ). The main reason for this was that many participants aged 55 years and older particularly overestimated their body height. The same findings were reported in a large Australian cohort study ${ }^{(12)}$ in which elderly persons (65 years and older) considerably overestimated their height. One possible reason why elderly people tend to overestimate their height could be that their height has actually changed due to osteoporosis and kyphosis, and these people report the height they had when they were younger.

Especially in the age groups less than 35 years and 35-44 years we found high agreement between reported and measured data. This coincides with the results of other surveys $^{(12,15,20)}$.

In previous studies, the use of self-reported values for determining the BMI category of subjects led to an underestimation of overweight and obesity $(10,13,22,23,28)$. In our present study, the prevalence for underweight and obesity was statistically significantly lower when operating with self-reported data. However, the prevalences of reported and measured underweight were nearly congruous $(1 \cdot 3 \% v \cdot 1 \cdot 5 \%)$. The underestimation of obesity was due to under-reported body weight and over-reported body height. Relying on self-reported data, the obesity prevalence was $12 \cdot 5 \%$. Anthropometric measurements, however, showed the true prevalence of obesity to be $15 \cdot 4 \%$. Similar results were found in a Dutch cross-sectional health monitoring survey, which investigated 3691 
adults $^{(13)}$. Here differences between reported and measured obesity prevalences were $3.3 \%$ in women and $3.0 \%$ in men. Surprisingly the prevalence for overweight was overrated in the present study. Nevertheless, the overall prevalence difference in the BMI category of overweight, based on self-reported $v$. measured BMI, was very low $(37 \cdot 4 \% v .37 \cdot 2 \%)$.

The strength of the current study was that the anthropometric measurements were performed with a standardized procedure by trained physicians and with a maximum time interval of $3 \mathrm{~h}$ between the self-reporting and measuring of weight and height. Limitations of the study include the fact that body weight was not measured to the nearest $100 \mathrm{~g}$, but in whole units of kilograms. Also height was only given in whole units of centimetres and not in millimetres. In our opinion the setting could also represent a limitation to the representativeness of the study. It seems likely that subjects who attend a health check rather report their true body weight and height. Perhaps there would have been less agreement between reported and measured data in other settings, as for example in surveys with participants at home. Therefore, we recommend further research be done on the validity of reported body weight and height in typical survey settings.

In conclusion, we found that self-reported BMI may be used as a very simple, inexpensive and less timeconsuming method when doing BMI estimates for overweight and obesity in epidemiological studies. Overall, our findings have shown self-reported body weight and height to be reasonably valid measures compared with measured values. Very high agreement was reached among younger adults. It should be noted that BMI accuracy is considerably influenced by age. We therefore conclude that there are limitations regarding the use of self-reported weight and height data of older adults. The use of self-reported data for BMI may induce bias in studies about overweight and obesity. We recommend investigations in other settings with larger study samples in order to provide a more detailed analysis of the validity of reported data on body weight and height.

\section{Acknowledgements}

This research received no specific grant from any funding agency in the public, commercial or not-for-profit sectors. There are no conflicts of interest to report. This paper represents a fully independent contribution by the authors. F.G. and W.J.S. were responsible for planning and conducting the study. F.G. did the literature review. B.H. was responsible for the organization at the setting. All authors participated in compilation of the manuscript. The authors wish to thank all contact persons and fieldworkers at the Institute of Preventive Medicine for their cooperation during the study. They also thank all persons who participated in the study.

\section{References}

1. World Health Organization (2008) Obesity in Europe. http://www.euro.who.int/obesity (accessed April 2011).

2. World Health Organization (2000) Obesity: Preventing and Managing the Global Epidemic. Report of a WHO Consultation. WHO Technical Report Series no. 894. Geneva: WHO.

3. Visscher TLS \& Seidell JC (2001) The public health impact of obesity. Annu Rev Public Health 22, 355-375.

4. World Health Organization (2009) Obesity and overweight. http://www.who.int/mediacentre/factsheets/fs311/en/index. html (accessed April 2011).

5. Peytremann-Bridevaux I \& Santos-Eggimann B (2008) Health correlates of overweight and obesity in adults aged 50 years and over: results from the Survey of Health, Ageing and Retirement in Europe (SHARE). Obesity and health in Europeans aged $>$ or $=50$ years. Swiss Med Wkly 138, 260-266.

6. Schulte H, von Eckardstein A, Cullen P et al. (2001) Übergewicht und kardiovaskuläres Risiko. Herz 26, 170-176.

7. Prentice AM (1997) Obesity - the inevitable penalty of civilisation? Br Med Bull 53, 229-237.

8. International Association for the Study of Obesity (2008) Overweight \& Obesity in the EU27. http://www.iaso.org/ site_media/uploads/v2PDFforwebsiteEU27.pdf (accessed April 2011).

9. Jackson E, Doescher MP, Jerant AF et al. (2005) A national study of obesity prevalence and trends by type of rural county. J Rural Health 21, 140-148.

10. Faeh D, Marques-Vidal P, Chiolero A et al. (2008) Obesity in Switzerland: do estimates depend on how body mass index has been assessed? Swiss Med Wkly 138, 204-210.

11. Ezzati M, Martin H \& Skjold S (2006) Trends in national and state-level obesity in the USA after correction for self-report bias: analysis of health surveys. J R Soc Med 99, 250-257.

12. Taylor AW, Dal Grande E \& Gill TK (2006) How valid are self-reported height and weight? A comparison between CATI self-report and clinic measurements using a large cohort study. Aust N Z J Public Health 30, 238-246.

13. Visscher TL, Viet AL \& Kroesbergen IH (2006) Underreporting of BMI in adults and its effect on obesity prevalence estimations in the period 1998 to 2001. Obesity (Silver Spring) 14, 2054-2063.

14. Cullum A, McCarthy A \& Gunnell D (2004) Dietary restraint and the misreporting of anthropometric measures by middle-aged adults. Int $J$ Obes Relat Metab Disord 28, 426-433.

15. Spencer EA, Appleby PN \& Davey GK (2002) Validity of self-reported height and weight in 4808 EPIC-Oxford participants. Public Health Nutr 5, 561-565.

16. Kuczmarski MF, Kuczmarski RJ \& Najjar M (2001) Effects of age on validity of self-reported height, weight and body mass index: findings from the Third National Health and Nutrition Examination Survey, 1988-1994. J Am Diet Assoc 101, 28-34.

17. Nawaz H, Chan W, Abdulrahman M et al. (2001) Selfreported weight and height. Implications for obesity research. Am J Prev Med 20, 294-298.

18. Flood V, Webb K, Lazarus R et al. (2000) Use of self-report to monitor overweight and obesity in populations: some issues for consideration. Aust $N Z J$ Public Health 24, 96-99.

19. Santillian AA \& Camargo CA (2003) Body mass index and asthma among Mexican adults: the effect of using selfreported vs measured weight and height. Int J Obes Relat Metab Disord 27, 1430-1433.

20. Glaesmer H \& Brähler E (2002) Prevalence estimation of overweight and obesity based on subjective data of bodymass-index (BMI). Gesundheitswesen 64, 33-138. 
21. Connor Gorber S, Tremblay M, Moher D et al. (2007) A comparison of direct vs self-report measures for assessing height, weight and body mass index: a systematic review. Obes Rev 8, 307-326.

22. Kovalchik S (2008) Validity of adult lifetime self-reported body weight. Public Health Nutr 12, 1072-1077.

23. Rossouw K, Senekal M \& Stander I (2000) The accuracy of self-reported weight by overweight and obese women in an outpatient setting. Public Health Nutr 4, 19-26.

24. World Health Organization (2006) BMI classification. http://apps.who.int/bmi/index.jsp?introPage =intro_3.html (accessed April 2011).
25. Bland JM \& Altman DG (1999) Measuring agreement in method comparison studies. Stat Methods Med Res 8, 135-160.

26. Grouven U, Bender R \& Ziegler A (2007) Comparing methods of measurement. Dtsch Med Wochenschr 132, e69-e73

27. Cuzick J (2006) A Wilcoxon-type test for trend. Stat Med $\mathbf{4}$, 87-90.

28. De Vriendt T, Huybrechts I, Ottevaere C et al. (2009) Validity of self-reported weight and height of adolescents, its impact on classification into BMI categories and the association with weighing behaviour. Int J Environ Res Public Health 6, 2696-2711. 